\title{
Fígado e luz. Uma combinação precisa, da mitologia à medicina
}

\section{The liver and light. A precise combination, from mythology to medicine}

\author{
Orlando de Castro e Silva Júnior ${ }^{1}$, Marina Rodrigues Garcia da Silveira²
}

\author{
Qual Prometeu tu me amarraste um dia \\ Do deserto na rubra penedia \\ - Infinito: galé! \\ Por abutre - me deste o sol candente, \\ E a terra de Suez - foi a corrente \\ Que me ligaste ao pé
}

\section{Castro Alves}

$\mathrm{D}$ iversos estudos do nosso grupo, ao longo dos últimos anos, têm mostrado interação efetiva da luz com tecidos biológicos, particularmente o fígado. ${ }^{1-4}$ Tanto a luz convencional, quanto o LED light-emitting diode- e o laser, com suas propriedades ópticas diferentes, promovem efeitos semelhantes nas organelas celulares levando ao aumento da eficiência da cicatrização de feridas, da capacidade energética mitocondrial hepatocelular e da regeneração hepática. ${ }^{1-7} \mathrm{O}$ fígado tem extraordinária capacidade de regeneração diante de vários tipos de desafios ou lesões. A perda tecidual rapidamente desencadeia o processo regenerativo até que o peso original seja recuperado. A constatação da resposta do fígado aos vários desafios, como as hepatites, as intoxicações, as ressecções hepáticas e o transplante de fígado, é mitológica ${ }^{8-12}$ e levanta aspectos extremamente interessantes sobre a coerência do fígado em superar desafios e vencer obstáculos.
Hesíodo relatou, em sua Teogônia, escrita no século VIII a.C., que Prometeu roubou o fogo escondido no Olimpo para entregá-lo aos homens. Para castigá-lo, Zeus enviou-lhe a bela Pandora, portadora de uma caixa que, ao ser aberta, espalharia todos os males sobre a Terra. Como Prometeu resistiu aos encantos dessa mensageira, Zeus ordenou que Vulcano o acorrentasse a um rochedo no cimo do monte Cáucaso, onde todos os dias uma águia (ou abutre) ia comer-lhe o fígado, que regenerava durante a noite, mantendo constante a fonte de alimento da ave, e Prometeu sob tortura perpétua. ${ }^{13}$ Teria a luz do luar, propriedades indutórias sobre a regeneração hepática, diferentes das do sol ? Talvez haja uma mensagem, implícita, neste sentido.

Apesar de Prometeu ser um titã, e dessa forma, imortal, o processo regenerativo do fígado, descrito nessa passagem da mitologia Grega, é a mais famosa e citada referência histórica nos trabalhos que se remetem ao processo de regeneração hepática na literatura médica. Na literatura brasileira, Castro Alves, na sua famosa Vozes D'Africa, de 1868, compara de forma poética o sofrimento eterno de Prometeu ao do território africano, deixando nas entrelinhas o poder de regeneração do fígado na manutenção da vida de Prometeu.

Estudos recentes, utilizando-se de hepatectomias parciais sequenciais, mostraram que o fígado é capaz de se regenerar completamente depois de
1. Professor Titular da Universidade de São Paulo e chefe do Departamento de Cirurgia e Anatomia da FMRP-USP

2. Acadêmica do terceiro ano e aluna de iniciação científica do Departamento de Cirurgia e Anatomia da FMRP-USP
Faculdade de Medicina de Ribeirão Preto - FMRP-USP Departamento de Cirurgia e Anatomia - HCFMRP-USP Av. Bandeirantes, 3.900 Ribeirão Preto, 14049-900 SP - Brasil

Artigo recebido em 13/09/2013 Aprovado para publicação em 27/09/2013 
12 intervenções, validando essa passagem da mitologia grega e mostrando a capacidade quase que ilimitada de regeneração desse órgão no qual um único hepatócito de ratos pode dividir-se pelo menos 34 vezes, levando a produção final de $1,7 \times 10^{10}$ células, quantidade suficiente para a geração de 50 fígados. Essa característica regenerativa mostra que os hepatócitos maduros não são células completamente diferenciadas. ${ }^{14}$

O fígado, além da característica de regeneração, é um órgão complexo e exerce diversas funções relacionadas com metabolismo, síntese, armazenamento, redistribuição de aminoácidos, proteínas, carboidratos, gorduras e vitaminas e ainda, desintoxicação: eliminação de xenobióticos e substâncias desnecessárias ao organismo, a conversão de amônia em uréia e ainda é responsável pela produção e excreção da bile. ${ }^{8,9,10}$

$\mathrm{Na}$ verdade, essas propriedades são as bases fundamentais da cirurgia hepática, ou seja, das ressecções hepáticas parciais e do transplante de fígado, que, ao crescer após um desafio, mantém sua vitalidade funcional e metabólica. Entretanto, nossos projetos de pesquisa têm procurado agentes que possam estimular o fígado a regenerar-se a limites além daqueles que ele naturalmente consegue, visando ampliar os limites da indicação do tratamento e melhorar os resultados terapêuticos. A luz tem se mostrado, do ponto de vista experimental, instrumento eficiente como bioestimulador do crescimento hepático após ressecções parciais ou transplantes de fígado. Com a luz, podemos estimular a capacidade energética hepatocelular e o crescimento do fígado, avaliar e medir esse crescimento, podemos usá-la como diagnóstico e ain$\mathrm{da}$, como fototerapia (figuras 1e 2). ${ }^{1,5,6,7,10,15-18}$
Conforme mostra a figura 3, foi possível estimular a regeneração hepática com a luz laser com todo o espectro de luz visível. ${ }^{7}$

Recentemente, conseguimos demonstrar que através da espectroscopia de fluorescência a laser é possível detectarmos o ganho de massa hepática durante o processo de regeneração hepática. Sem entrar em detalhes, é possível também induzir necrose tumoral com a luz laser pela associação dessa com substâncias fotosensiblizadoras, produzindo radicais livres de oxigênio e morte de células neoplásicas. ${ }^{1,15}$

$O$ raio laser é um sistema que amplifica a intensidade de luz, produzindo um feixe, altamente direcionado com o comprimento de onda específico, sendo marco histórico a publicação de On The Quantum Theory of the Radiation por Albert Einsten em 1917. A palavra laser significa "Light Amplification by Stimulated Emission of Radiation”. Em julho de 1960, foi anunciado o funcionamento do primeiro laser, cujo meio ativo era um cristal de rubi. A partir daí, o laser obteve progressiva aplicação em vários setores, inclusive na Medicina. ${ }^{2}$ Em 1972, começaram a ser descritos os efeitos biológicos do laser quando consta-

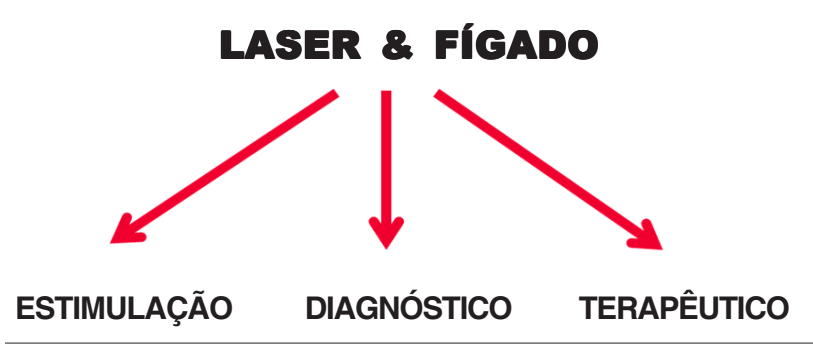

Figura 1: Possibilidades da resultante da interação laser e fígado.

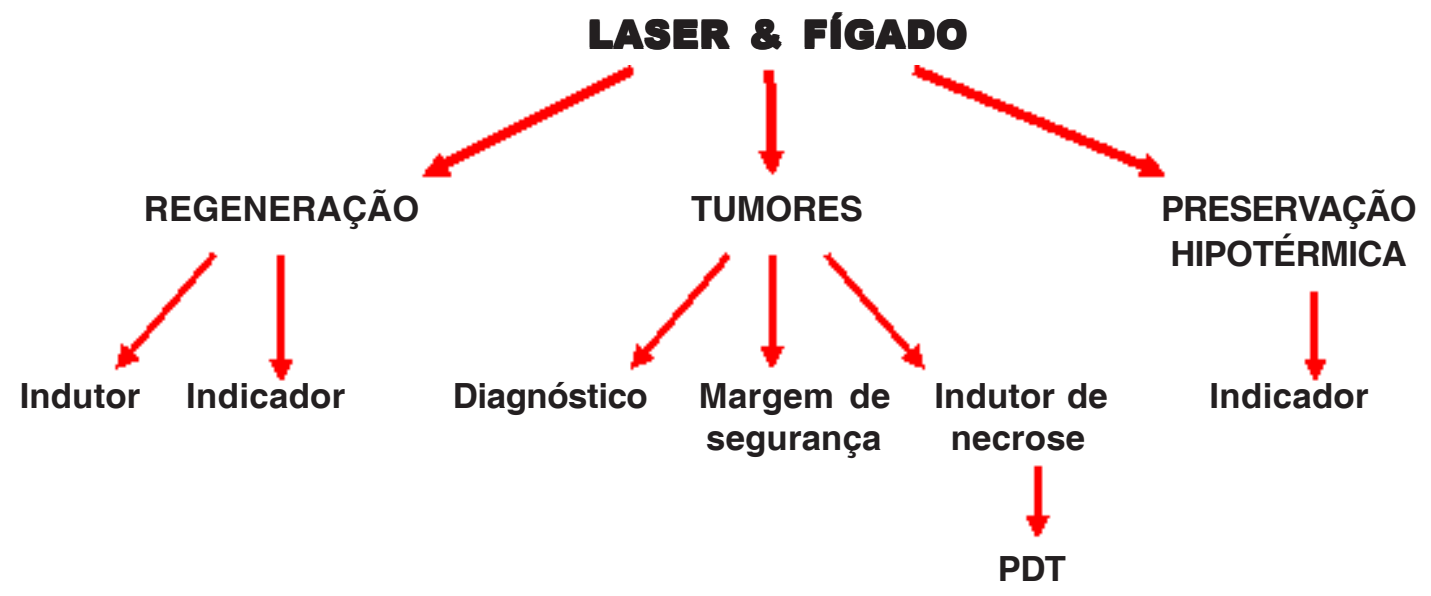

Figura 2: Tipos de aplicação do laser em cirurgia, clínica e experimental 
tou-se o estímulo ao processo cicatricial em feridas cirúrgicas submetidas à irradiação laser de baixa potência. Denominou-se o novo campo como fotobioestimulação. ${ }^{2,6,7}$ A fototerapia com laser mostrou-se eficaz no tratamento de úlceras de membros inferiores, na neoformação vascular, proliferação de fibroblastos, reparo ósseo, regeneração de nervos, ${ }^{19}$ tendo também vasta aplicação em oncologia sob a denominaçao de terapia fotodinâmica. ${ }^{17}$

Os mecanismos de interação do laser com a matéria são caracterizados como fotoquímicos, fototérmicos e fotomecânicos. A fotobioestimulação baseia-se no nível mais sutil de interação da luz com tecidos, em que o fóton transmite sua energia a um composto fotossensível. ${ }^{4-17}$ Pressupõe-se que a luz laser conduza a alterações conformacionais na estrutura dos citocromos dos hepatócitos, de modo que haveria um incremento na produção de ATP, expressando um aumento no metabolismo energético de fígado de ratos hepatectomizados. ${ }^{16,20}$ Foi demonstrado que a luz laser, tanto de alta quanto baixa potência, tem a capacidade de elevar o índice mitótico e função mitocondrial no remanescente hepático após ressecções parciais em ratos não cirróticos. Relatou-se que o índice mitótico se eleva de $15-20 \%$ nas hepatecto- mias sem aplicação de laser, para 50-55\%, quando sucedidas de irradiação. ${ }^{6,7,16,20}$

Karu $^{21}$ teoriza que a mitocôndria contém fotorreceptores e que a absorção de luz pelos componentes da cadeia respiratória causaria ativação desta, culminando com a produção de energia celular (ATP). Entretanto, os locais de ação específicos do laser na célula não estão ainda estabelecidos, havendo muitas questões no referente à sua base ultraestrutural. ${ }^{22,23}$

Novos estudos poderão dar, literalmente, luz nova aos conhecimentos existentes. Em projeto recentemente desenhado em nosso grupo, é intenção avaliar o efeito da luz laser sobre o fígado em condições hipotérmicas ex-situ, sem contato com o corpo do hospedeiro. Desta forma, o fígado remanescente após hepatectomia de $70 \%$ e privado dos fatores hepatotróficos, receberia da luz laser uma influência estimulatória ou inibitória? Fato é que, estimulando ou inibindo um crescimento já detectado mas ainda não publicado, novas perguntas serão geradas para o estabelecimento de novos estudos. A mitologia aponta, em sua essência, para um caminho, entretanto deve haver muita luz em vários túneis que necessitarão ser abertos pra atingirmos nossas metas e objetivos. E essa é a idéia.

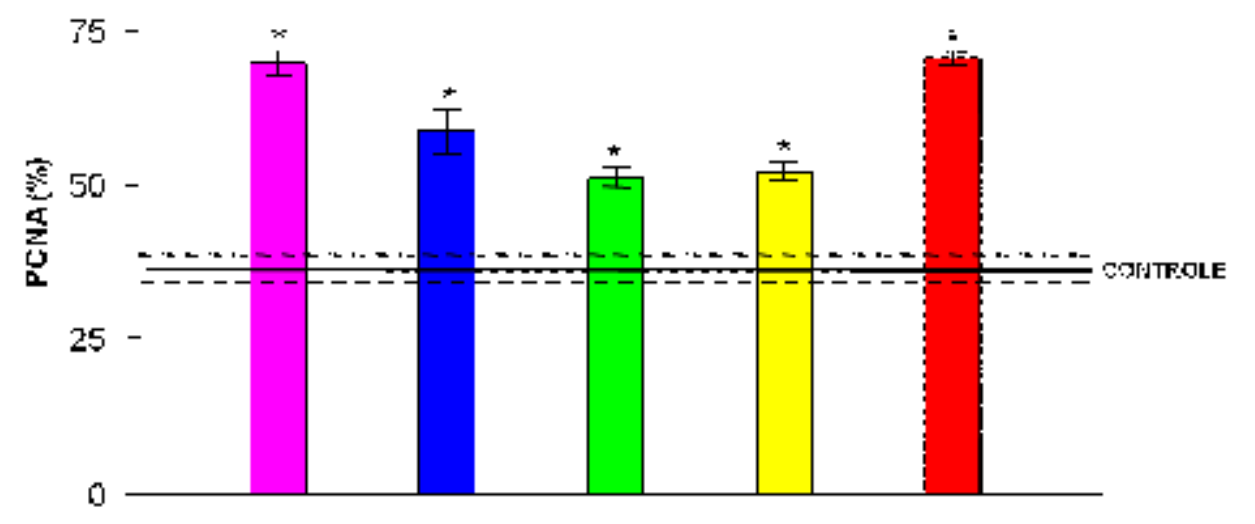

Figura 3: Regeneração hepática em resposta 'a estimulação do laser nos respectivos comprimentos de onda de luz visível. ${ }^{7}$ 


\section{Referências}

1. Melo CA, Lima AL, Brasil IR, Castro e Silva O Jr, Magalhães DV, Marcassa LG, Bagnato VS. Characterization of light penetration in rat tissues. J Clin Laser Med Surg. 2001; 19:175-9.

2. Bagnato VS, Kurachi C,Ferreira J, Sankarankutty AK, Zucoloto $\mathrm{S}$, de Castro e Silva O. New photonic technologies for the treatment and diagnosis of hepatic diseases:an overview of the experimental work performed in collaboration, between Physics Institute of São Carlos and Ribeirão Preto Faculty of Medicine, Acta Cir Bras. 2006;21:3-11.

3. Oliveira AF, Silva TC, Sankarankutty AK, Pacheco EG, Ferreira J, Bagnato VS, Zucoloto S, Silva OdeC. The effect of laser on remanescent liver tissue after $90 \%$ hepatectomy in rats. Acta Cir Bras. 2006;21:29-32.

4. Bagnato VS, Kurachi C, Castro e Silva O. New perspectives for optical techniques in diagnostic and treatment of hepatic diseases. Acta Cir Bras. 2010;25:214-6.

5. Melo GB, Silva RL, Melo VA, Lima So, Antoniolli AR, Castro e Silva T, Marcassa LG, Bagnato VS, Zucoloto S, Ramalho LN, Ramalho FS, Castro e Silva O Jr. Enhancement of liver regeneration by the association of Hyptis pectinata with laser therapy. Dig Dis Sci. 2005;50:949-54.

6. Castro e Silva Júnior O, Zucoloto S, Bagnato VS, Marcassa LG, Menegazzo LAG, Granato RG. Laser enhancement in hepatic regeneration for partially hepatectomized rats. Lasers Surg Med. 2001;29:73-7.

7. Castro e Silva O Jr, Zucoloto S, Marcassa LG, Marcassa J, Kurachi C, Melo CA, Ramalho FS, Ramalho LN, Bagnato VS. Spectral response for enhancement in hepatic regeneration for hepatectomized rats. Lasers Surg Med. 2003; 32: 50-3.

8. Fausto N. Liver regeneration. J Hepatol. 2000;32:19-31.

9. Mortensen KE, Revhaug A. Liver regeneration in surgical animal models - A historical perspective and clinical implications. Eur Surg Res. 2011;46:1-18.

10. Miyaoka Y, Miyajima A. To divide or not to divide: revisiting liver regeneration. Cell Div. (Lond.). 2013; 8:1-12.

11. Yuan Q, Loya K, Rani B, Mobus S, Balakrishnan A, Lamle J, Cathomen T, et al. MicroRNA-221 overexpression accelerates hepatocyte proliferation during liver regeneration. Hepatology. 2013; 57: 299-310.
12. Simpson GEC, Finckh ES. Pattern of regeneration of rat liver after repeated partial hepatectomies. J Pathol Bacteriol. 1963;86:361-70.

13. Hesíodo. Teogonia / Os trabalhos e dias. Tradução de Pinheiro AE, Ferreira JR. Lisboa: Imprensa Nacional, 2005.

14. Overturf K, Al-Dhalimy M, Finegold M, Grompe M. The repopulation potential of hepatocyte populations differing in size and prior mitotic expansion. Am J Pathol. 1999;155:213543.

15. Ferraz RC, Ferreira J, Menezes PF, Sibata $\mathrm{CH}$, Castro e Silva O Jr, Bagnato VS. Determination of threshold dose of photodynamic therapy to measure superficial necrosis. Photomed Laser Surg. 2009;27:93-9.

16. Castro e Silva O, Prozillo LC, Potenciano O, Mucillo G, Zucoloto $\mathrm{S}$. The Effect Of Low-Energy He-Ne Laser Irradiation On Liver Regeneration. Res Sur. 1991;3:192-3.

17. Castro e Silva O, O S J, Ramalho LZ, Zilio S, Bagnato VS, Granato RG, et al. Aspectos Basicos da Regeneracao Hepatica e O Papel da Luz Laser e Convencional Como Agentes Estimulantes. Acta Cir Bras. 1996;11:14-6.

18. Melo GB, Silva RL, Melo VA, Lima SO, Antoniolli AR, Castro e Silva $\mathrm{T}$, et al. Enhancement of liver regeneration by the association of Hyptis pectinata with laser therapy. Dig Dis Sci. 2005; 50:949-54.

19. Mester E, Mester AF, Mester A. The biomedical effects of LASER application. Lasers Surg Med. 1985; 5:31-9.

20. Lima AALA. Efeito da irradiação laser sobre o fígado de ratos cirróticos submetidos à hepatectomia parcial. Ribeirão Preto, 2001. 73p [Tese de Mestrado]. Faculdade de Medicina de Ribeirão Preto, Universidade de São Paulo.

21. Karu T. Photobiology of low-power laser effects. Health Phys. 1989;56:691-704.

22. Baxter GD. Therapeutic Lasers: Theory and practice. Churchill Livingstone Inc., 1994.

23. Castro e Silva O, Menegazzo LAG, Granato RG, Bagnato VS, Zílio S, Zucoloto S. Luz Laser e Tecidos Biológicos. Da Experimentação à Aplicação Clínica. Estudo Atual e Perspectivas. Acta Cir Bras. 1997; 12: 34-6. 